\title{
CARDIOVASCULAR CHANGES IN PSORIASIS
}

\author{
Nasir Naazneen¹, Manikoth Payyanadan Binitha², Neduvanchery Tahsin³, Mangalath Narayanan Krishnan ${ }^{4}$ \\ ${ }^{1}$ Senior Resident, Department of Dermatology and Venereology, Government Medical College, Kozhikode, Kerala, India. \\ ${ }^{2}$ Additional Professor, Department of Dermatology and Venereology, Government Medical College, Kozhikode, Kerala, India. \\ ${ }^{3}$ Senior Resident, Department of Cardiology, Government Medical College, Kozhikode, Kerala, India. \\ 4 Professor and HOD, Department of Cardiology, Government Medical College, Kozhikode, Kerala, India.
}

\section{ABSTRACT}

\section{BACKGROUND}

It is now widely accepted that patients with psoriasis have an increased likelihood of developing cardiovascular complications.

Aim of this study was to identify the possible increased incidence of cardiovascular risk factors and the prevalence of cardiovascular disorders in individuals with psoriasis.

\section{MATERIALS AND METHODS}

The study was conducted in the first 40 patients who attended the outpatient department between October 2010 and October 2011. The presence of cardiovascular risk factors and diseases was assessed based on the history, examination findings and relevant investigations. The data obtained were compared with that in the normal population using appropriate statistical measures.

\section{RESULTS}

More patients in the study group had statistically significant diabetes mellitus ( $p=0.023)$ and impaired fasting glucose ( $p=0.017)$ when compared to the normal population. The abdominal obesity in males was found to be statistically significant $(p=0.0009)$ when compared to the normal population.

\section{CONCLUSION}

Early detection of cardiovascular involvement and appropriate intervention in psoriasis patients is recommended for a favourable outcome.

\section{KEYWORDS}

Psoriasis, Cardiovascular Changes.

HOW TO CITE THIS ARTICLE: Naazneen N, Binitha MP, Tahsin N, et al.Cardiovascular changes in psoriasis. J. Evolution Med. Dent. Sci. 2016;5(98):7175-7179, DOI: 10.14260/Jemds/2016/1624

\section{BACKGROUND}

Psoriasis is a disorder associated with chronic inflammation. It can also be related to inflammatory states in other systems, particularly the cardiovascular system (CVS). In addition, studies indicate that there is an increased incidence of cardiovascular risk factors such as smoking, alcoholism, obesity, hypertension, hyperlipidaemia, diabetes mellitus and metabolic syndrome in patients with psoriasis,[1] which aggravate the deleterious effects on the CVS. This study was done with the aim of evaluating the prevalence of cardiovascular disorders in psoriasis patients and the prevalence of cardiovascular risk factors in these patients.

\section{MATERIALS AND METHODS}

This was a cross sectional study performed after obtaining approval of the protocol from the institutional ethics committee. Forty consecutive patients suffering from psoriasis attending the Department of Dermatology and Venereology in

Financial or Other, Competing Interest: None.

Submission 03-11-2016, Peer Review 28-11-2016,

Acceptance 03-12-2016, Published 08-12-2016.

Corresponding Author:

Dr. Manikoth Payyanadan Binitha,

Haritha, Post Beypore,

Kozhikode-673015, Kerala,

India.

E-mail:mpbinitha@gmail.com

DOI: $10.14260 /$ jemds $/ 2016 / 1624$ our tertiary care public hospital between October 2010 and October 2011 were studied. Patients with psoriatic erythroderma, or psoriasis limited to palms and soles, or cardiac disorders prior to the onset of psoriasis were excluded from the study.

Detailed medical histories were recorded with special reference to cardiovascular risk factors. Height and weight were recorded, and body mass index (BMI) calculated to determine the presence of obesity. A detailed assessment of the CVS was done under the guidance of a cardiologist. As studies have shown that patients with severe psoriasis are more at risk of developing cardiovascular disorders, the extent of cutaneous involvement was assessed by PASI score.

All patients were subjected to routine laboratory examination of blood and urine, fasting and postprandial blood sugar levels, (FBS and PPBS), fasting lipid profile, renal and liver function tests, electrocardiography and echocardiography. They were investigated for hypertension, diabetes mellitus, dyslipidaemia, obesity, abdominal obesity, metabolic syndrome, coronary artery disease (CAD), ECG and echo changes.

Hypertension was defined as blood pressure $\geq 140 / 90 \mathrm{~mm}$ of mercury or a previously diagnosed case of hypertension on antihypertensives. Diabetes mellitus was defined as FBS $\geq 126$ $\mathrm{mg} \%$ or PPBS $\geq 200 \mathrm{mg} \%$ or previously diagnosed diabetes on treatment. Dyslipidaemia was defined as total cholesterol $>$ $200 \mathrm{mg} / \mathrm{dL}$ or LDL $>130 \mathrm{mg} / \mathrm{dL}$ or triglycerides $\geq 150 \mathrm{mg} / \mathrm{dL}$ 
or VLDL $>40 \mathrm{mg} / \mathrm{dL}$ or $\mathrm{HDL}<40 \mathrm{mg} / \mathrm{dL}$ in men or $<50 \mathrm{mg} / \mathrm{dL}$ in women.

Obesity was defined as BMI $\geq 30$, and abdominal obesity was defined as waist circumference $\geq 90 \mathrm{~cm}$ in males and $\geq 80$ $\mathrm{cm}$ in females.

\section{Metabolic Syndrome was Diagnosed if a Patient had at} Least Three of the following Five Conditions

1. Fasting glucose $\geq 100 \mathrm{mg} / \mathrm{dL}$ or receiving drug therapy for hyperglycaemia.

2. Blood pressure $\geq 130 / 85 \mathrm{~mm}$ of mercury or receiving drug therapy for hypertension.

3. Triglycerides $\geq 150 \mathrm{mg} / \mathrm{dL}$ or receiving drug therapy for hypertriglyceridaemia.

4. HDL-C $<40 \mathrm{mg} / \mathrm{dL}$ in men or $<50 \mathrm{mg} / \mathrm{dL}$ in women, or receiving drug therapy for reduced HDL-C.

5. Waist circumference $\geq 102 \mathrm{~cm}$ in men or $\geq 88 \mathrm{~cm}$ in women.

\section{Statistical Analysis}

The results of the study were expressed in proportions and percentages (mean \pm standard deviation). Cardiovascular changes in different grades of psoriasis were compared using Chi square test for trend (for qualitative variables) and ANOVA (for quantitative variables). Comparison of psoriatic patients with the normal population was done by using Chi square test (for qualitative variables) and ' $\mathrm{t}$ ' test (for quantitative variables). A ' $\mathrm{p}$ ' value $\leq 0.05$ was considered statistically significant.

\section{RESULTS}

Of the 40 patients enrolled in the study, 33 were male and 7 were female. Their ages ranged from 15 to 79 years with a mean age of 48.95 . The majority of the patients were in their fifth decade of life, with a second peak at the seventh decade. The duration of the disease ranged from one month to 30 years, with an average of 9.1 years. The age of onset of the disease ranged from 12 to 70 years, with a mean of 39.1 years. Associated arthralgia was present in $10(25 \%)$ patients. A history of erythroderma was present in four patients (10\%). Twenty six patients $(65 \%)$ had received systemic treatment for psoriasis - 25 of them methotrexate and one was on systemic retinoids. The most common site of involvement was the trunk [Figure 1], and the least affected sites were the palms and soles. No mucosal involvement was seen in our patients. The most common type of skin lesion was the chronic plaque type. Nail changes were observed in 34 patients (85\%). The PASI score ranged from 3.2 to 55.8 , with a mean value of 25.34 [Table 1].

\section{Cardiovascular Risk Factors}

Smoking: Thirty five percent of the patients, all of them male, were smokers. This prevalence was not found to be statistically significant, as the prevalence rate of smoking in the male population of Kerala has been reported to be $30.6 \% .{ }^{[2]}$

\section{Hypertension}

Hypertension was present in 15 (37.5\%) patients, 14 of them male. Of these, $11(73.3 \%)$ were diagnosed after the onset of psoriasis. Only $4(26.7 \%)$ had hypertension prior to the onset of psoriasis. This prevalence was not found to be statistically significant, as the prevalence rate is $36.1 \%$ in the population. ${ }^{2]}$

There was no statistically significant correlation between PASI score and duration of the disease with the presence of hypertension.

\section{Diabetes Mellitus}

Eleven patients $(27.5 \%)$ were diabetic, 9 of them male. This prevalence was statistically significant $(p=0.023)$. [2] Of these, $6(54.5 \%)$ were diagnosed after the onset of psoriasis, and 5 $(45.5 \%)$ had diabetes prior to the onset of psoriasis. The presence of diabetes did not correlate significantly with the duration of the disease or the PASI score.

Six (15\%) patients had impaired fasting glucose (IFG) (FBS 100-125 mg\%), of which 5 were male and one female. The prevalence was statistically significant, $(p=0.017)$ compared with the prevalence of $5.1 \%$ in the population.[2]

Obesity and excess weight: Obesity was found in only one female patient $(2.5 \%)$, whereas $10(25 \%)$ patients were overweight (BMI 25.1 - 29.9). This was not statistically significant compared to the prevalence of $51.1 \%$ in the population.[2]

Abdominal obesity was found in 26 (65\%). Of the 33 male patients, 20 (60.6\%), and of the 7 female patients, $6(85.7 \%)$ had abdominal obesity. The prevalence of abdominal obesity in males was statistically significant.[3]

\section{Dyslipidaemia}

Elevated total cholesterol levels were seen in 12 (30\%) of the male patients and $4(10 \%)$ of the female patients. Triglyceride levels were elevated in $8(20 \%)$ of the male patients but in none of the female patients. Raised LDL levels were seen in 12 $(30 \%)$ of the male and $4(10 \%)$ of the female patients. Reduced HDL values were noted in one $(2.5 \%)$ male and $3(7.5 \%)$ female patients. Raised VLDL levels were seen in 2 (5\%) male and none of the female patients. The alterations in the lipid profile did not have any statistically significant correlation with the prevalence in the general population, the PASI score or the duration of the disease.

\section{Metabolic Syndrome}

This was observed in 13 (32\%) patients, 10 male and 3 female. There was no statistically significant difference when compared to the general population.

\section{Cardiovascular Disease}

A history of myocardial infarction (MI) was present in 5 (12.5\%) patients. All were male and had MI after the onset of psoriasis. All the 5 patients had hypertension, 4 had diabetes, 3 had dyslipidaemia and 2 were smokers.

One male patient had a history of stroke after the onset of psoriasis.

\section{ECG Changes}

$\mathrm{T}$ wave inversion was seen in 8 male and 3 female patients, ST depression in one, $\mathrm{Q}$ waves in 2 , and left ventricular hypertrophy (LVH) in 4 male patients.

\section{Echocardiography Findings}

The ejection fraction was $>50$ in $37(92.5 \%)$ patients, indicating good ventricular function, and between 45 and 50 in $3(7.5 \%)$ patients, indicating mild ventricular dysfunction. 
LVH was detected in 3 (7.5\%), and mild left ventricular diastolic dysfunction in $2(5 \%)$ male patients. Two male patients had regional wall motion abnormalities (RWMA), which indicated ischaemic changes.

In total, $15 \%$ of our patients had coronary artery disease (CAD), which was not found to be statistically significant [Table 2].

\section{Our Study Revealed}

1. A statistically significant association between psoriasis and abdominal obesity, diabetes and IFG values, when compared with the general population.

2. A high prevalence of cardiovascular risk factors such as smoking, hypertension, obesity, dyslipidaemia and metabolic syndrome in patients with psoriasis.

3. Occurrence of CAD in psoriatic patients with a prevalence as high as $15 \%$.

\begin{tabular}{|c|}
\hline Patient Characteristics \\
\hline Total no. of patients 40 \\
\hline Mean age in years 48.95 \\
\hline Mean age at onset in years 39.1 \\
\hline Mean duration of psoriasis in years 9.1 \\
\hline Mean PASI score 25.34 \\
\hline Table 1. Patient Characteristics \\
\hline
\end{tabular}

*PASI: Psoriasis Area Severity Index

\begin{tabular}{|c|c|c|c|}
\hline $\begin{array}{c}\text { Cardiovascular } \\
\text { Risk Factors }\end{array}$ & $\begin{array}{l}\text { Males } \\
(n=33)\end{array}$ & $\begin{array}{c}\text { Females } \\
(n=7)\end{array}$ & $\begin{array}{c}\text { Total } \\
(n=40)\end{array}$ \\
\hline Smoking & $14(42.4)$ & - & $14(35)$ \\
\hline Hypertension & $14(42.4)$ & $1(14.3)$ & $15(37.5)$ \\
\hline $\begin{array}{l}\text { Diabetes } \\
\text { Mellitus }\end{array}$ & 9 (27.3) & $2(28.6)$ & $11(27.5)$ \\
\hline $\mathrm{IFG}^{*}$ & $5(15.2)$ & $1(14.3)$ & $6(15.0)$ \\
\hline Obesity & - & $1(14.3)$ & $1(2.5)$ \\
\hline Overweight & & & $10(25.0)$ \\
\hline $\begin{array}{l}\text { Abdominal } \\
\text { Obesity }\end{array}$ & $20(60.6)$ & $6(87.5)$ & $26(65.0)$ \\
\hline Dyslipidaemia & $12(36.4)$ & $4(57.2)$ & $16(40.0)$ \\
\hline $\begin{array}{l}\text { Metabolic } \\
\text { Syndrome }\end{array}$ & $10(30.3)$ & $3(42.9)$ & $13(32.0)$ \\
\hline $\mathrm{MI} \dagger$ & $5(15.2)$ & - & $5(12.5)$ \\
\hline Stroke & $1(3.0)$ & - & $1(2.5)$ \\
\hline LVH & $3(9.1)$ & - & $3(7.5)$ \\
\hline RWMA§ & $2(6.1)$ & - & $2(5.0)$ \\
\hline LV Dysfunctionll & $4(12.2)$ & - & $4(10.0)$ \\
\hline \multicolumn{4}{|c|}{$\begin{array}{c}\text { Table 2. Prevalence of Cardiovascular Risk Factors in } \\
\text { the Study Population }\end{array}$} \\
\hline
\end{tabular}

(Figures in the parentheses indicate column wise percentages)

*IFG: Impaired Fasting Glucose †MI: Myocardial Infarction $\neq$ LVH: Left Ventricular Hypertrophy §RWMA: Regional Wall Motion Abnormality

IILV Dysfunction: Left Ventricular Dysfunction

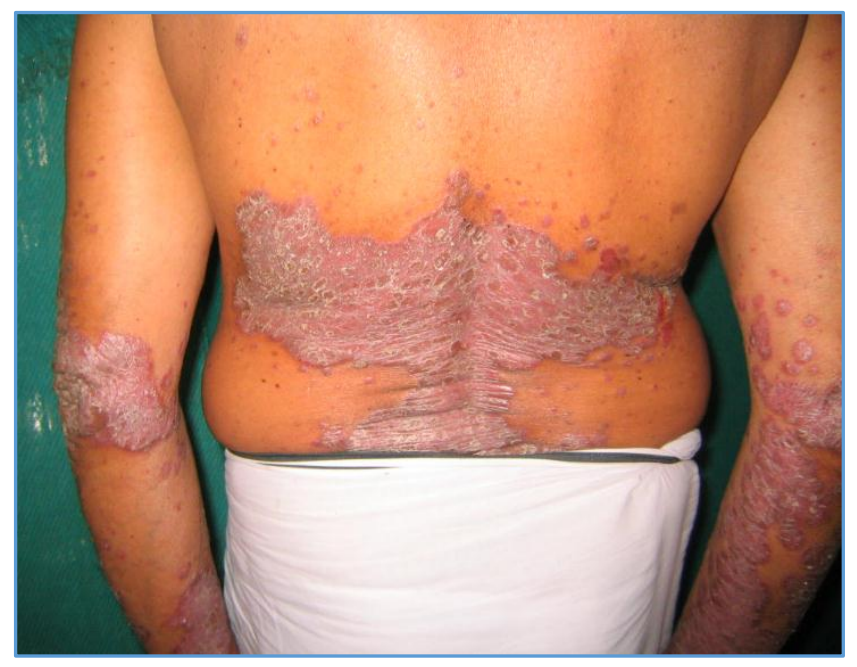

Figure 1. Psoriasis on the Trunk

\section{DISCUSSION}

The CV morbidity in psoriatic patients is dependent on the severity of the skin involvement, with deleterious effects reported mainly in severe psoriasis.[1] These patients have an increased incidence of insulin resistance, obesity, hypertension, dyslipidaemia and metabolic syndrome.

Patients with severe psoriasis have an increased risk of atherothrombosis, ${ }^{[4]}$ stroke and atrial fibrillation, ${ }^{[5]}$ as well as arterial and venous vascular diseases such as thrombophlebitis, pulmonary embolisation,[6] coronary artery calcification,[7] and myocardial infarction. ${ }^{[8]}$

Multiple common pathogenic features are involved in this link between psoriasis and cardiovascular morbidity. These include:

A predilection for insulin resistance is seen in patients with psoriasis due to many inter-linked factors. These include elevated levels of tumour necrosis factor- $\alpha,{ }^{[9]}$ inhibition of tyrosine kinase activity of the insulin receptor, and suppression of adiponectin secretion from adipocytes.[10]

Patients with psoriasis have decreased peroxisome proliferator-activated receptor delta (PPAR $\delta$ ), which is responsible for metabolic syndrome in these patients. Reduced PPAR $\delta$ is associated with diabetes, hypertension, insulin resistance and dyslipidaemia.[11]

Obesity leads to secretion of multiple inflammatory cytokines by adipose tissue, especially leptin, which is associated with atherosclerosis and arterial thrombosis. Hyperleptinaemia has also been demonstrated in psoriasis.[12] Hypertension: Psoriasis has been demonstrated to be associated with polymorphisms in inflammation genes such as the angiotensin converting enzyme (ACE) gene.[13]

Elevated plasma renin activity ${ }^{[14]}$ and increased levels of endothelin-1[15] have been reported in patients with psoriasis, leading to the development of hypertension. Endothelin-1 is produced by keratinocytes as an autocrine growth factor and is a potent vasoconstrictor.

Inflammatory cytokines in psoriasis such as interferongamma produced by Th1 cells and interferon- 17 produced by Th17 cells cause inflammation involving interferon-gamma, tumour necrosis factor, and interleukins.[16] These cytokines also are involved in the process of atherosclerosis and acute coronary syndrome.[17] 
Increased levels of cytokines such as IL- 6 and TNF- $\alpha$ lead to increased levels of C-reactive protein (CRP) in psoriasis. Increased levels of CRP lead to an increased risk for adverse cardiac events such as acute myocardial infarction (AMI), unstable angina, hypertension, MI and stroke.[18]

Intercellular adhesion molecule-1 (ICAM-1) and vascular cell adhesion molecule-1 (VCAM-1) are upregulated in psoriasis, and are also involved in the formation of atherosclerotic plaques. Vascular endothelial growth factor (VEGF) is upregulated and leads to angiogenesis in both psoriasis and atherosclerosis.[18]

Naïve T cells activated by antigen-presenting cells in the lymph nodes interact with dendritic cells, macrophages and keratinocytes in psoriasis, and with smooth muscle cells in atherosclerosis, leading to the development of psoriatic or atherosclerotic plaques.[18]

Common genetic loci of susceptibility PSORS2, PSORS3 and PSORS4 have been demonstrated for psoriasis, metabolic syndrome, type 2 diabetes, familial hyperlipidaemia and cardiovascular disease.[19] Individual genes such as CDKAL1 are associated with psoriasis and type 2 diabetes, $[20]$ and Apolipoprotein E with psoriasis and hyperlipidaemia.[21,22] Increased serum levels of homocysteine in psoriasis and the associated dyslipidaemia lead to atherothrombosis in these patients.[4]

High circulating levels of osteopontin occur in psoriasis, which is also associated with atherosclerosis. [23]

Oxidative stress is greatly increased in psoriasis, in conjunction with an abnormal lipid profile, leading to increased risk of cardiovascular disease. [24]

Systemic drugs used to treat psoriasis such as retinoids and cyclosporine can cause hyperlipidaemia and hypertension.

The increased priority given to treatment of psoriasis leads to decreased attention to the presence or development of CV risk factors.

Studies on patients with psoriasis have demonstrated statistically significant abnormal findings on electrocardiography, the most common being ST-T wave changes. The intima-media thickness of both common carotid arteries was found to be significantly higher in these patients indicating subclinical atherosclerosis.[25] Psoriasis could also be a risk factor for hypertension and cardiovascular disease even in the absence of metabolic syndrome.[26]

\section{CONCLUSION}

Based on the results of our study, we recommend regular monitoring of patients with psoriasis for the presence of comorbidities which have a definite adverse effect on both psoriasis and the CVS. Early detection and control of these risk factors is imperative to reduce the morbidity and mortality associated with these conditions, and to provide a better quality of life to these patients.

\section{REFERENCES}

1. Neimann AL, Shin DB, Wang $X$, et al. Prevalence of cardiovascular risk factors in patients with psoriasis. J Am Acad Dermatol 2006;55(5):829-35.

2. Vijayakumar G, Arun R, Kutty VR. High prevalence of type 2 diabetes mellitus and other metabolic disorders in rural Central Kerala. J Assoc Physicians India 2009;57:563-7.
3. Thankappan KR, Shah B, Mathur P, et al. Risk factor profile for chronic non-communicable diseases: results of a community-based study in Kerala, India. Indian J Med Res 2010;131:53-63.

4. Kural VB, Orem A, Cimsit G, et al. Plasma homocysteine and its relationships with atherothrombotic markers in psoriatic patients. Clin Chim Acta 2003;332(1-2):23-30.

5. Ahlehoff $\mathrm{O}$, Gislason $\mathrm{GH}$, Jorgensen $\mathrm{CH}$, et al. Psoriasis and risk of atrial fibrillation and ischaemic stroke: a Danish nationwide cohort study. Eur Heart J 2012;33(16):205464.

6. Mcdonald CJ, Calabresi P. Psoriasis and occlusive vascular disease. Br J Dermatol 1978;99(5):469-75.

7. Ludwig RJ, Herzog C, Rostock A, et al. Psoriasis: a possible risk factor for development of coronary artery calcification. Br J Dermatol 2007;156(2):271-6.

8. Xiao J, Chen LH, Tu YT, et al. Prevalence of myocardial infarction in patients with psoriasis in central China. J Eur Acad Dermatol Venereol 2009;23(11):1311-5.

9. Reich K. The concept of psoriasis as a systemic inflammation: implications for disease management. J Eur Acad Dermatol Venereol 2012;26(Suppl 2):3-11.

10. Azfar RS, Gelfand JM. Psoriasis and metabolic disease: epidemiology and pathophysiology. Curr Opin Rheumatol 2008;20(4):416-22.

11. Heqazy RA, Hay ARM, Shaker 0, et al. Psoriasis and metabolic syndrome: is peroxisome proliferator-activated receptor- $\delta$ part of the missing link? Eur J Dermatol 2012;22(5):622-8.

12. Armstrong AW, Herskamp CT, Armstrong EJ. The association between psoriasis and obesity: a systematic review and meta-analysis of observational studies. Nutr Diabetes 2012;2:e54.

13. Liu T, Han Y, Lu L. Angiotensin-converting enzyme gene polymorphisms and the risk of psoriasis: a meta-analysis. Clin Exp Dermatol 2013;38(4):352-8.

14. Ena P, Madeddu P, Glorioso N, et al. High prevalence of cardiovascular diseases and enhanced activity of the reninangiotensin system in psoriatic patients. Acta Cardiol 1985;40(2):199-205.

15. Bonifati C, Mussi A, Carducci M, et al. Endothelin-1 levels are increased in sera and lesional skin extracts of psoriatic patients and correlate with disease severity. Acta Derm Venereol 1998;78(1):22-6.

16. Ghoreschi K, Weigert $\mathrm{C}$, Röcken M. Immunopathogenesis and role of $\mathrm{T}$ cells in psoriasis. Clinics in Dermatology 2007;25(6):574-80.

17. Correale M, Brunetti ND, Di Biase M. The pro-inflammatory role of cytokines in the mechanism of atherosclerosis. $G$ Ital Cardiol (Rome) 2006;7(9):594-603.

18. Ghazizadeh $R$, Shimizu $H$, Tosa $M$, et al. Pathogenic mechanisms shared between psoriasis and cardiovascular disease. Int J Med Sci 2010;7(5):284-9.

19. Bowden DW, Rudock M, Ziegler J, et al. Coincident linkage of type 2 diabetes, metabolic syndrome, and measures of cardiovascular disease in a genome scan of the diabetes heart study. Diabetes 2006;55(7):1985-94.

20. Quaranta M, Burden AD, Griffiths CE, et al. Differential contribution of CDKAL1 variants to psoriasis, Crohn's disease and type II diabetes. Genes \& Immunity 2009;10(7):654-8. 


\section{Jemds.com}

21. Campalani E, Allen MH, Fairhurst D, et al. Apolipoprotein E gene polymorphisms are associated with psoriasis but do not determine disease response to acitretin. Br J Dermatol 2006;154(2):345-52.

22. Eichner JE, Dunn ST, Perveen G, et al. Apolipoprotein E polymorphism and cardiovascular disease: a huge review. Am J Epidemiol 2002;155(6):487-95.

23. Chen YJ, Shen JL, Wu CY, et al. Elevated plasma osteopontin level is associated with occurrence of psoriasis and is an unfavorable cardiovascular risk factor in patients with psoriasis. J Am Acad Dermatol 2009;60(2):225-30.

24. Rocha-Pereira P, Santos-Silva A, Rebelo I, et al. Dyslipidemia and oxidative stress in mild and in severe psoriasis as a risk for cardiovascular disease. Clin Chim Acta 2001;303(1-2):33-9.

\section{Original Research Article}

25. Kothiwala SK, Khanna N, Tandon N, et al. Prevalence of metabolic syndrome and cardiovascular changes in patients with chronic plaque psoriasis and their correlation with disease severity: a hospital-based crosssectional study. Indian J Dermatol Venereol Leprol 2016;82(5):510-8.

26. Pereira RR, Amladi ST, Varthakavi PK. A study of the prevalence of diabetes, insulin resistance, lipid abnormalities, and cardiovascular risk factors in patients with chronic plaque psoriasis. Indian J Dermatol 2011;56(5):520-6. 